\title{
ECOLOGICAL STUDIES ON THE WHITE PEACH SCALE INSECT PSEUDAULACASPIS PENTAGONA (TARGIONI-TOZZETTI) (HEMIPTERA: DIASPIDIDAE)
}

\author{
MOHAMED, G. H., ZINAT K. MOHAMMAD AND \\ FATMA ABD-ELHALIM MOHARUM
}

Plant Protection Research Institute, ARC, Dokki, Giza

(Manuscript received 15 June 2008)

\begin{abstract}
This study included population dynamics of Pseudaulacaspis pentagona (Targioni-Tozzetti) (Hemiptera: Diaspididae) on peach, Prunus persica L. at Qualyobia governorate, on plum, Plum demestica L. at Giza governorate and on apple, Malus sylvestris Mill. at El-Beheira governorate. The study was conducted over two successive years in each site. The age structure method was used to determine the number of generations. Obtained trend over the study period indicated the occurrence of three generations per year for $P$. pentagona on peach and plum at Qualyobia and Giza locations. The three generations were nominated as spring, summer and fall-winter generations. The first one spring generation expanded from approximately Jan. to May. The second summer generation expanded from May. to Aug. and the third fall-winter generation expanded from Aug. to next Feb. Obtained results on apple at El-Noubaria location indicated two generations per year. They were nominated as summer and fall-winter generations. This insect overwintered as mature females. Population densities of this diaspidid were the greatest in fall-winter generation. The population of the spring generation was higher than the summer one. Great intensity of $P$. pentagona in fall-winter generation coincided with the vegetative cycle or phase before interring dormancy in winter (deciduous fruit trees). The spring generation expanded mainly on terminal branches and new twigs (where no fruits have been formed yet and the insect does not infest the leaves at high numbers). Summer generation coincided with the fruit forming phases with lowest general population.
\end{abstract}

\section{INTRODCTION}

Peach, Prunus persica L., plum, P. demestica L. and apple, Malus sylvestris Mill. (Family Rosaceae), are deciduous fruits (stone $\&$ pome fruits) and considered to be among the most important fruit crops in Egypt.

The diaspidid white peach scale, Pseudaulacaspis pentagona (Targioni-Tozzetti) (Hemiptera: Diaspididae) is one of the principal armoured scale pests in the world (Beardsley \& Gonzalez, 1975). It is a polyphagous pest with very wide host plant range, especially on fruit trees and ornamental plants including peach, plum and apple trees in many parts of the world (Kosztarab \& Kozar, 1988). P. pentagona is one of the most important scale insect pests which cause serious damage to fruit trees in 
many parts of the world. The infestation by this insect is mainly concentrated on the trunk, branches, twigs and moves to fruits. When occurs, injury is caused by different stages of the insect. They suck plant sap and cause wilting of twigs, death of branches, defoliation and considerable yield loss (Pan et al., 2003).

Gardonna and Viggiani (1988), Brailoiu (1998), Kreiter and Dijoux (1998), Nalepa and Meyer (1990), Battgalia et al. (1994), Bianchi et al. (1995), Zhou and Zhou (1999) and Pan et al. (2003) showed that P. pentagona had three complete generations a year. In the mean time, Ding and Ding (2003) showed that $P$. pentagona had four generations per year, while Chen and Shih (1984) observed six generations per year for the same species.

Mohamed (2002) and Serag (2005) determined the number of generations of Parlatoria oleae (Colvee), Lepidosaphes ficus (Signoret), Hemiberlesia latania (Signoret) and Russellaspis pustulans (Cockerell) (Hemiptera: Diaspididae) on olive and fig trees in Egypt using age structure method. They reported three generations for $P$. oleae on olive, $L$. ficus and $H$. lataniae on fig while reported two generations only for $R$. pustulans on the same host.

The main aim of this work was to study the seasonal abundance and generation determination of $P$. pentagona on peach, plum and apple over two successive years at each of Kafr Shokr (Qualyobia governorate), El-Saff (Giza governorate) and ElNoubaria (El-Beheira governorate), respectively.

\section{MATERIALS AND METHODS}

Population dynamics of $P$. pentagona were carried out on peach, plum and apple at Qualyobia, Giza and El-Beheira governorates during Dec. 1, 1999 to Nov. 15, 2001, Feb. 15, 2000 to Feb. 1, 2002 and Mar. 1, 2000 to Feb. 15, 2002, respecticvely. The selected orchards did not receive any chemical control for many years before starting monitoring and within studying period. All trees received the same routine horticultural practices by their owners. Selected ten trees were similar in size, shape, height and vegetation as possible. Trees of each host plant were homogenous in their infestation with $P$. pentagona. Samples were picked up twice a month throughout the two successive years of study. Samples were picked up from cardinal directions (north, south, east and west) and tree core of each selected tree. Sample size was 10 $\mathrm{cm}$ of 4-6 $\mathrm{mm}$ in diameter of primary branches and $5 \mathrm{~cm}$ of $9-11 \mathrm{~mm}$ in diameter for secondary branch. Samples were replicated four times. Samples were picked up from each sampled tree using a garden scissors. The samples were packed immediately in perforated paper bags and transferred to the laboratory directly on the same day for examination, using stereoscopic microscope. 
Alive stages found on each sample were assorted and recorded as: crawlers, pre-adult females, females, ovipositing females (gravid females) and pre-adult males.

Age-structure, generation determination and required degree-days, the number of generations of $P$. pentagona were estimated using the obtained data throughout the two successive years using the age-structure technique per year on each host plant per site.Generation is defined, as the time required for an insect to complete its life cycle, (i.e. egg to egg). In the case of diaspidids, eggs are oviposited under the female shield until they hatch and crawl out. The only way to detect ovipositon is by removal of the female shield. Gravid females are defined as females that have their eggs under their shields. The presence of gravid females (i.e. the transformation of females to gravid females) is considered under this study as presence of the egg stage. This phenomenon was used to determine the end of each generation and the beginning of the next one. The absolute number of each stage per sample per count can vary dramatically from one count to another. The difference between counts can be contributed to actual change in insect's population as well as sampling errors. To magnify the proportion of each stage per total, age-structure technique was used in these studies.

To calculate the age-structure per sample, the mean number of each stage was divided by the total and multiplied by 100 . This way gave each stage a percent proportion of the total per sample regardless the total number of insect present (i.e. degree of infestation). The beginning and ending of each generation was determined graphically by plotting the age-structure values versus time.

\section{RESULTS}

\section{Population dynamics of Pseudacaspis pentagona and generation determination}

To facilitate the presentation of data, each of the three host plants (i.e. peach, plum and apple located at Kafr Shokr, El-Saff, and El-Noubaria, respectively) will be discussed separately.

\section{Population dynamics on peach}

During 1999/2000 year, the mean insect count per sample was 89.79, 61.69, 74.59, 32.18 and 45.28 individuals for crawlers, pre-adult females, females, gravid females and pre-adult males, respectively. Crawlers' density per sample was highest on Sep. 15, 2000 (336.42 crawlers /sample). High abundance as 174.73 and 136.34 crawlers/sample occurred on Mar.15 and Jul. 1, 2000, respectively. Low populations were recorded on Dec. 1, 1999, May 1 and Aug. 1, 2000. Pre-adult females' density was highest on Oct. 1, 2000 as 259.76 pre-adult females/sample. Similar and earlier 
peaks occurred on Apr. 1 and Jul. 15, 2000. Lowest population of pre-adult females was observed during Dec. 1, 1999. Female's density reached its maximum on Oct. 15, 2000 as 200.21 females/sample.

Another period for female's high density occurred on Apr. 15 and Aug. 1, 2000 as 96.31 and 109.49 females/sample, respectively. Lowest females' density occurred during Dec. 1, 1999, May 15 and Sept. 1, 2000. Gravid female density was highest on Sept. 1, 2000 as 85.34 females/sample. Similar and earlier peaks occurred on Feb. 15, and May 15, 2000. Pre-adult males maximum density was recorded on Oct. 1, 2000 as 196.46 pre-adult males/sample. Another maximum density occurred on Apr. 1 and Jul. 15, 2000 as 101.58 and 75.86 pre-adult males/sample, respectively.

Mean of total population per sample had maximum values of $840.34,441.09$ and 385.28 individuals/sample on Oct. 1, Apr. 1 and Jul. 15, 2000, respectively. Lowest total population occurred on Dec. 1, 1999 May 1, and Nov. 15, 2000, respectively (Fig.1).

During 2000/2001 the mean insect's count per sample was 103.6, 77.53, 82.66, 28.18 and 43.83 individuals/sample of crawlers, pre-adult females, females, gravid females and pre-adult males, respectively. Crawlers' density per sample was highest on Oct. 1, 2001 as 334.49 individuals/sample, respectively. Fewer crawlers' abundance (as 0.2, 36.54 and 43.96 crawlers/sample) occurred on Dec. 15, 2000, May 15 and Aug. 15, 2001, respectively. Pre-adult female's density was highest on Oct. 15, 2001 as 278.34 pre-adult females/sample. Similar and earlier peaks occurred on Apr. 15 and Jul. 1, 2001, respectively. Lowest population of pre-adult female was observed during Dec. 15, 2000. Another depression was observed during Jul. 1 and Aug. 15, 2001.

Females' density reached its maximum on Nov. 1, 2001 as 218.73 females/sample. Another period for female's high density occurred on May 1 and Aug. 1, 2001 as 118.36 and 100.46 females/sample. Lowest females' density occurred during the periods of Dec.15, 2000, Jun. 1 and Sept. 15, 2001. Gravid female's density was highest on Sept. 1, 2001 as 100.96 females / sample. Similar and earlier peak occurred during Mar. 1, 2001 and another one on May 15, 2001. Lowest population of gravid females was observed during Dec. 15, 2000. Another depression was observed during Apr. 15 and Jun. 15, 2001. Pre-adult male counts were maximum occurrence was on Oct. 15, 2001 as 162.31 pre-adult males/sample. Another maximum occurrence was on Apr. 15 and Jul. 15, 2001as 73.58 and 76.16 pre-adult males/sample, respectively.

Total population per sample had maximum values of $897.93,444.45$ and 428.92 on Oct. 15, Apr. 1 and Jul. 15, 2001, respectively. Lowest mixed population occurred during Dec. 1, 2000 to Feb. 1, 2001 (Fig. 2). 


\section{Population dynamics on plum}

The obtained means of insect counts on plum were less than the observed on peach. During 2000/2001 the mean number per sample was 69.81, 62.91, 57.08, 22.01 and 32.81 individuals/sample of crawlers, pre-adult females, females, gravid females and pre-adult males of $P$. pentagona, respectively. Crawlers' density per sample was highest on Sept. 1, 2000 as 271.15 individuals/sample. High densities also occurred on Mar. 1 and Jun. 1, 2000 as 145.24 and 129.04 individuals/sample. Less abundance as 23.76, 28.56 and 0.15 crawlers/sample occurred on Apr. 15, 2000, Jul. 15 and Dec. 15, 2000, respectively. Pre-adult female density was highest on Sept. 15, 2000 as 213.69 pre-adult females /sample. Similar and earlier peaks occurred on Mar. 15 , and Jun. 15, 2000. Low population of pre-adult females was observed on Jun. 1 , Nov. 15, 2000 to Feb. 1, 2001.

Females' density reached its maximum on Oct. 15, 2000 as 118.42 females/sample. Other maximum female densities occurred during Apr. 1 and Jul. 15, 2000 as 76.37 and 72.59 females / sample, respectively. Lowest female density occurred during the period of Nov. 15, 2000 to Feb. 1, 2001. Gravid females' density was highest on Aug. 15, 2000 as 74.69 gravid females / sample. High densities of gravid females occurred on Feb. 15 and May 1, 2000 as 46.34 and 41.37 gravid females /sample, respectively. Pre-adult males maximum occurrence was on Oct. 1 , 2000 as 123.64 pre-adult males/sample. Another maximum occurred on Apr. 1 and Jul. 1,2000 as 51.32 and 53.23 pre-adult males/sample, respectively. individuals per sample had maximum values of 639.10, 350.94 and 270.95 on Sept. 1, Mar. 1 and Jul. 1, 2000. Lowest population occurred during Nov. 15, 2000 to Feb. 1, 2001(Fig.3). 


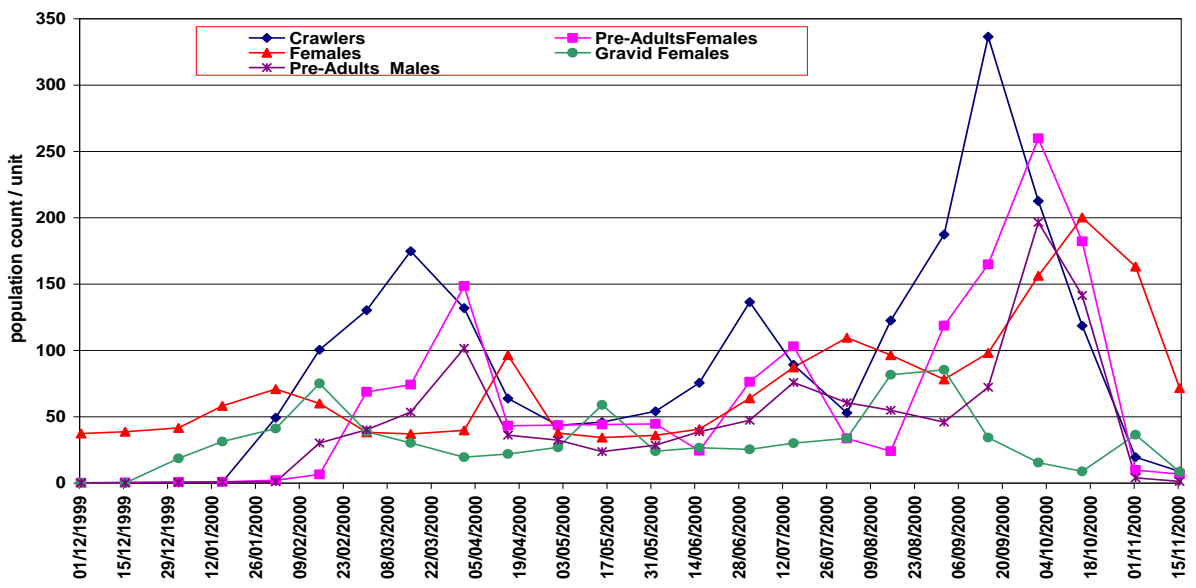

Fig . 1. Mean population count of pseudaulacaspis pentagona on peach trees during Dec. 99 to Nov. 2000 at Kafr Shokr, Qalubia, Governorate.

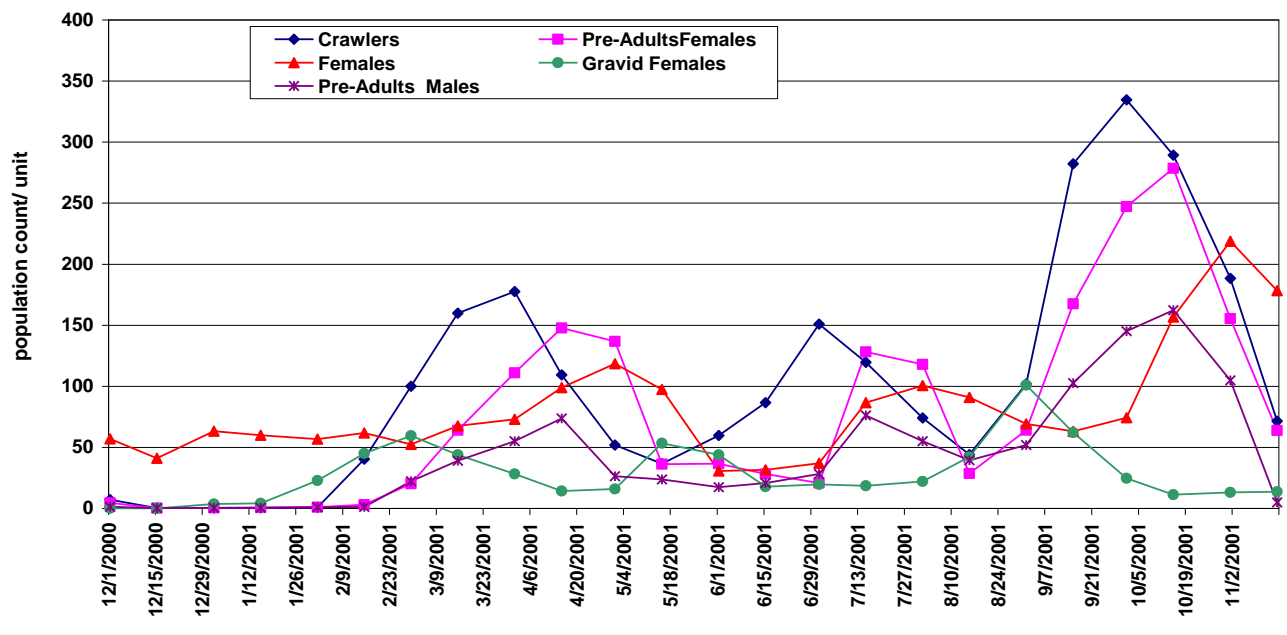

Fig. (2): Mean population count of P. pentagona on peach trees during Dec. 2000 to Nov. 2001 at Kafr Shokr, Qualyobia, Governorate.

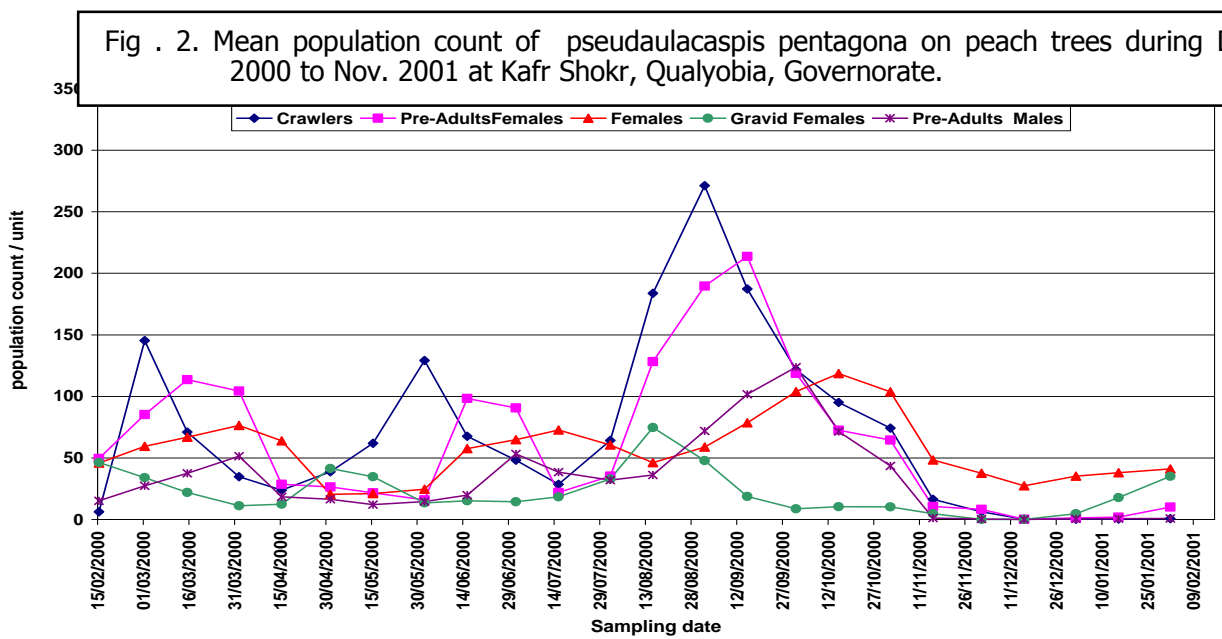

Fig. (3): Mean population count of $P$. pentagona on plum trees during Feb. 2000. to Feb. 2001 at El-Saff, Giza, governorate.

Fig . 3. Mean population count of pseudaulacaspis pentagona on plum trees during Feb. 2000 to Feb. 2001 El- Saff, Giza, Governorate. 
During 2001/2002 the mean number per sample was $81.27,69.2,64.86,27.07$ and 30.70 individuals of crawlers, pre-adult females, females, gravid females and preadult males of $P$. pentagona, respectively. Crawlers' density per sample was highest on Sept. 15, 2001 as 305.87 individuals/sample. High densities of crawlers occurred on Mar. 15 and May 15, 2001 as 161.95 and 147.69 individuals/sample. Less abundance as 41.27, 34.27 and 1.98 crawlers/sample occurred on Apr. 15, 2001, Jul. 15 and Dec. 1, 2002, respectively. Pre-adult females density per sample was highest on Sept. 15, 2001 as 234.37 individuals/sample. High population occurred on Apr. 1 and Jun. 1, 2001 as 129.13 and 103.18 individuals/sample, respectively. Less abundance as 10.57, 11.93 and 0.45 pre-adult females/sample occurred on Feb. 15, May 15 and Jul. 15, 2001, respectively. Females' density reached its maximum during Apr. 1, Jul. 1 and Nov. 1, 2001 as 92.71, 79.84 and 139.01 females/sample, respectively. Low females density occurred during the period of Feb. 15, May 15 and Aug. 15, 2001 (less than the average).

Gravid females' Maximum occurrence was on Mar. 1, Apr. 15 and Sept. 1, 2001 as 53.81, 45.52 and 89.65 females/sample, respectively. Pre-adult males' maximum values occurrence were on May 1, Jul. 15 and Oct. 1, 2001 as 57.23, 47.87 and 115.39 pre-adult males/sample, respectively.

Total individual per sample had maximum values of 765.86 and 395.39 on Sept. 15 and Mar. 15, 2001. Lowest general population occurred during Dec. 1, 2001 to Feb. 1, 2002 (Fig.4).

\section{Population dynamics on apple}

During 2000/2001 the mean insect number per sample was $65.12,54.27,60.53$, 28.95 and 25.91 individuals of crawlers, pre-adult females, females, gravid females and pre-adult males of $P$. pentagona, respectively. Crawlers' density per sample was highest on May 15 and Sept. 15, 2000 as 166.47 and 236.61 individuals/sample. Lowest population occurred during Mar. 1 to Apr. 15, 2000 and Nov. 1, 2000 to Feb. 15,2001 , respectively. Pre-adult females' density was highest on Jun. 1 and Oct. 1 , 2000 as 131.96 and 186.43 pre-adult females/sample. Lowest population of pre-adult females was observed during Mar. 1, to Apr. 15, 2000. Another depression was observed during Dec. 1 to Feb. 15, 2001. Females' density reached its maximum on Nov. 1, 2000 as 128.93 adult females/sample. Another period for females' high density occurred on Jun. 15, 2000 as 108.72 females/sample. Lowest females' density occurred during Sept. 15, 2000 and Feb. 15, 2001. Gravid females' density was highest on Apr. 1 and Aug. 15, 2000 as 50.46 and 72.36 gravid females/sample. Lowest population of gravid females was observed during Dec. 15, 2000 to Feb. 15, 
2001. Pre-adult male's maximum density occurrence was on Jun. 1 and Oct. 1, 2000 as 57.43 and 89.32 pre-adult males/sample, respectively.

Total individual per sample had maximum values of 527.94 and 425.56 on Oct. 1 , and Jun. 1, 2000, respectively. Lowest general mixed population occurred during Dec. 15, 2000 to Feb. 15, 2001(Fig.5).

During 2001/2002 the mean number per sample was $70.54,50.31,56.43,27.38$ and 40.64 individuals of crawlers, pre-adult females, females, gravid females and preadult males of $P$. pentagona, respectively. Crawlers' density reached its maximum on Sept. 1, 2001 as 252.31 crawlers/sample. Another period for crawlers' high density occurred on May 1, 2001 as 173.02 crawlers/sample. Low crawlers' density occurred during the period of Mar. 1 to Apr. 15, 2001 and Nov. 15, 2001 to Feb. 15, 2002. Preadult females density per sample was highest on May 15 and Sept. 152001 as 189.78 and 137.94 individuals/sample. Less abundance as 6.14 and 37.85 occurred on Mar. 1 and Aug. 1, 2001. Lowest population occurred in the duration of Jan. 15 to Feb. 15 2002. Females' density reached its maximum on Oct. 1, 2001, as 172.07 females/sample. Other period for female high density occurred on Jun. 1, 2001 as 125.12 females/sample. Low female density occurred during the period of Mar. 1 and Aug.15, 2001. Gravid females' density was highest on Apr. 1 and Aug. 1, 2001 as 52.19 and 79.85 females/sample. Lowest population of gravid females was observed during Mar. 1 to Mar. 15, 2001. Another depression was observed during Nov. 15 to Feb. 15, 2002. Pre-adult males' maximum occurrence was on May 15 and Sep. 15, 2001 as 102.92 and 143.85 pre-adult males/sample, respectively.

Total individual per sample had maximum values of 486.97 and 623.81, occurring on Jun. 1 and Sept. 15, 2001. Lowest general population occurred during Dec. 1, 2001 to Feb. 15, 2002 (Fig.6). 


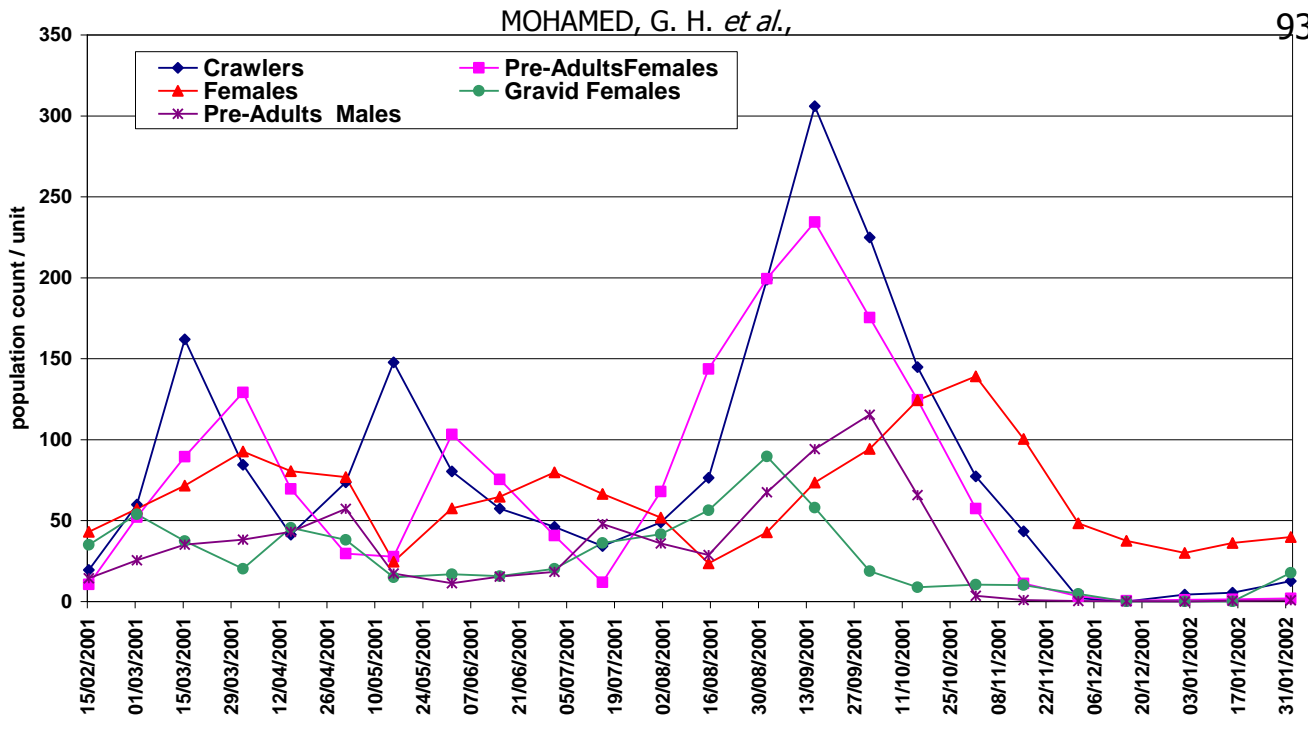

Sampling date

Fig . 4. Mean population count of pseudaulacaspis pentagona on plum trees during feb. 2001 to 15 feb. 2002 at El-Saff, Giza, governorate.

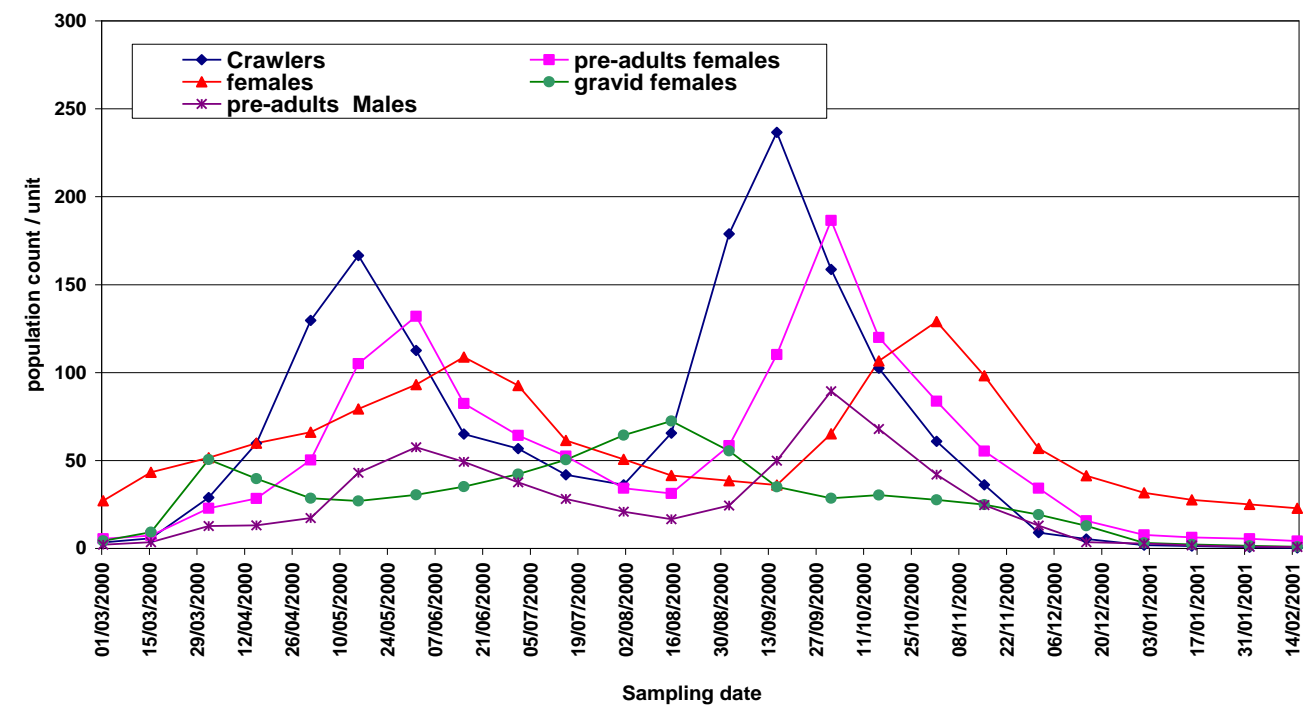

Fig . 5. Mean population count of pseudaulacaspis pentagona on apple trees during feb. 2001 to 15 feb. 2002 at El-Saff, Giza, governorate.

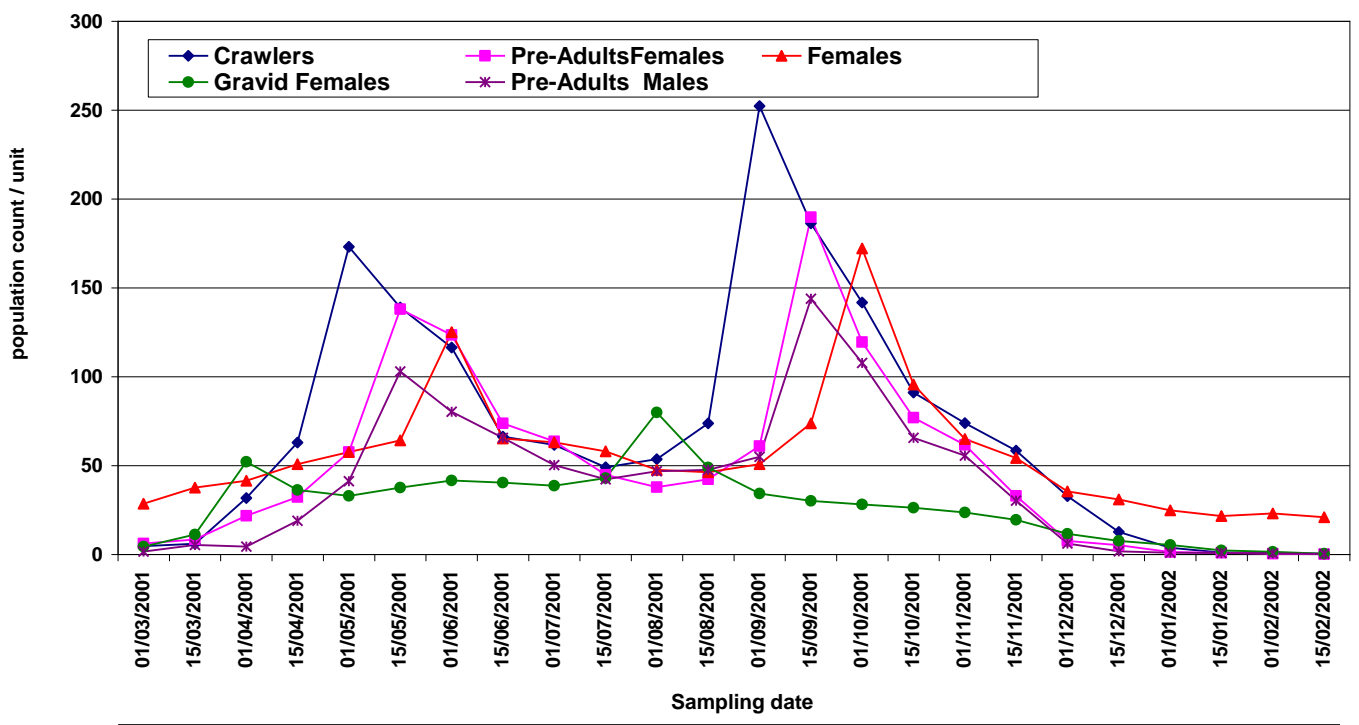

Fig . 6. Mean population count of pseudaulacaspis pentagona on apple trees during Mar. 2001 to 15 feb. 2002 at El-Saff, Giza, governorate. 


\section{Age-structure and generation determination}

The number of generations of $P$. pentagona was estimated using the obtained data throughout the two successive years using the age-structure technique per year on each host plant per site.

Obtained result through both studies years indicated the occurrence of three generations per year for $P$. pentagona on peach and plum at Qualyobia and Giza location. These three generations were nominated as spring, summer and fall-winter generations. In the mean time, obtained trend over both years indicated the occurrence of two generations per year on apple at El-Noubaria location. These two generations were nominated as summer, and fall-winter generations.

During the first year for $P$. pentagona on peach, the spring generation was determined to start by Jan. 1, 2000 up till end of Apr. 30, 2000. The summer generation started on May 1, 2000 and continued up till re-emergence of gravid females on Aug. 1, 2000. The fall-winter generation started on Aug. 1, 2000 to the next Feb. This means that the spring generation continued over 121 days compared with the summer generation which continued only for 92 days and the rest of the year was occupied by the fall-winter generation (i.e. 184 days) (Fig.7). Over the second year of study similar results were obtained with some delay. The relevant dates were Feb. 1, May 15 and Aug. 15, 2001. These obtained results suggested 104 and 92 days for spring and summer generations, respectively (Fig. 8).

During the first year for $P$. pentagona on plum the part of past spring generation was ended by May 1 . The summer generation started thereafter and continued up till Aug. 1, 2000 followed by fall-winter generation. This means that the part of spring generation continued over 75 days compared with the summer generation which continued only for 92 days and the rest of the year was occupied by the fall-winter generation (i.e. 178 days) (Fig. 9). Over the second year of study similar results were obtained. The relevant dates were May 1, Aug. 1, 2001 and Jan. 15, 2002. These obtained results suggested 105, 92 and 178 days for spring, summer and fall-winter generations, respectively (Fig. 10).

During the first year for $P$. pentagona on apple, the fall-winter generation continued up to Apr. 1, 2000. The summer generation started from this point up till Aug. 1, 2000. Therefore the date of Aug. 1, 2000 was considered as the start point for the next fall-winter generation. The summer generation continued over 122 days compared with 244 days for the fall-winter generation (Fig. 11). Over the second year of study similar results were obtained. The relevant dates were Apr. 1 and Aug. 1, 2001. These obtained results suggested 122 days for summer generation (Fig. 12). 


\section{DISCUSSION}

\section{Population dynamics and generation determination}

World wide it has been reported that $P$. pentagona has two to four generations depending on the host plant and the location. Obtained results in this study indicated three generations for $P$. pentagona on peach and plum at Qualyobia and Giza locations. The first generation (spring generation) expanded from approximately Jan. to May. The second generation (summer generation) expanded from May. to Aug. The third generation (fall-winter generation) expanded from Aug. to next Feb. This insect overwintered as mature females.

Population densities of this diaspidid were greatest in fall-winter generation. The population of the spring generation was higher than the summer one. Great intensity of $P$. pentagona in fall-winter generation coincided with the vegetative cycle or phase before interring dormancy in winter (deciduous fruit trees).

The spring generation expanded mainly on terminal branches and new twigs (where no fruits have been formed yet and the insect does not infest the leaves at high numbers). Summer generation coincided with the fruit forming phases with lowest general population.

These results are in agreement with Erklic et al. (1995) on peach in Turkey, Battaglia et al. (1994) on peach in Italy, Zhou and Zhou (1999) on peach in China, Pan et al. (2003) on plum in China, Nalepa and Meyer (1990) on peach in North Carolina, Kreiter and Dijoux (1998) on peach in South-Eastern France. Bianchi et al. (1995) on kiwi fruit in Italy,

Obtained results indicated also two generations for $P$. pentagona on apple at Nobaria location. The first generation (summer generation) expanded from approximately Apr. to Agu. The second generation (fall-winter generation) expanded from Aug. to next Apr. where it overwintered as mature females.

These results are in agreement with Gardonna and Viggiani (1988) on peach in Campania, Italy, Erklic et al. (1995) on peach in Turkey, Brailoiu (1998) on mulberry in Romania, Ding and Ding (2003) in China reported four generations on plum.

In an extreme case Chen and Shih (1984) recorded six generations in Taiwan on mulberry. It seems that the differences in generation's number depend on the host plant and climatic zone. 


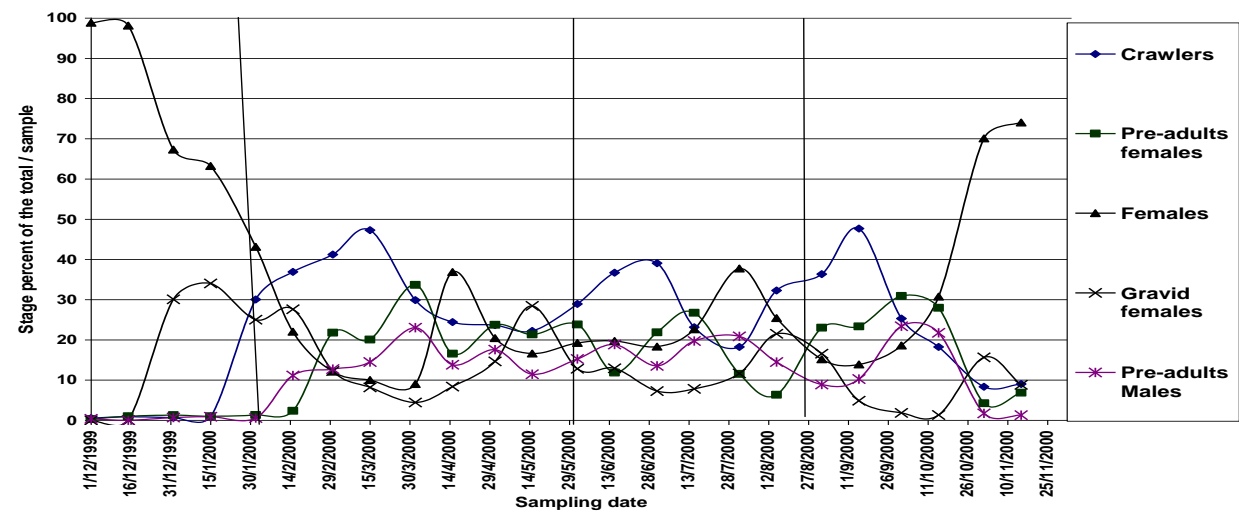

Fig . 7. Age-structure of pseudaulacaspis pentagona on peach trees during Dec. 99 to Nov. 2000 at Kafr Shokr, Qalubia, Governorate.

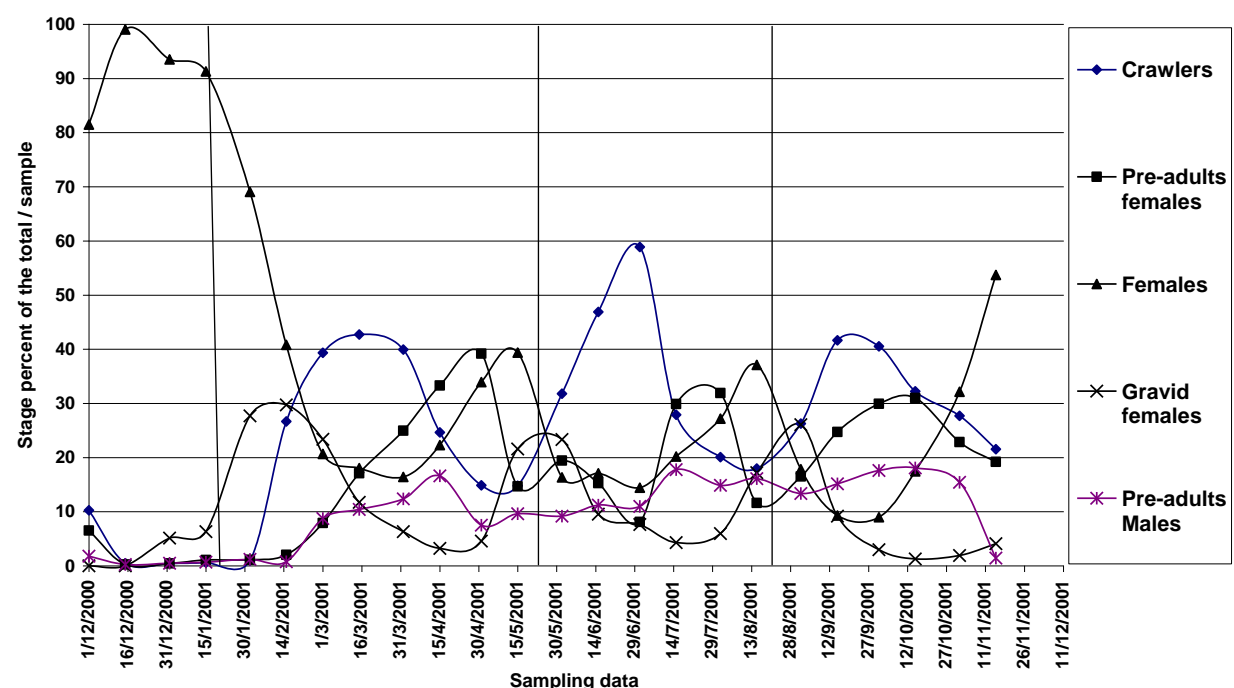

Fig . 8. Age-structure of pseudaulacaspis pentagona on peach trees during Dec. 2000 to 15 Nov. 2001 at Kafr Shokr, Qalubia, Governorate.

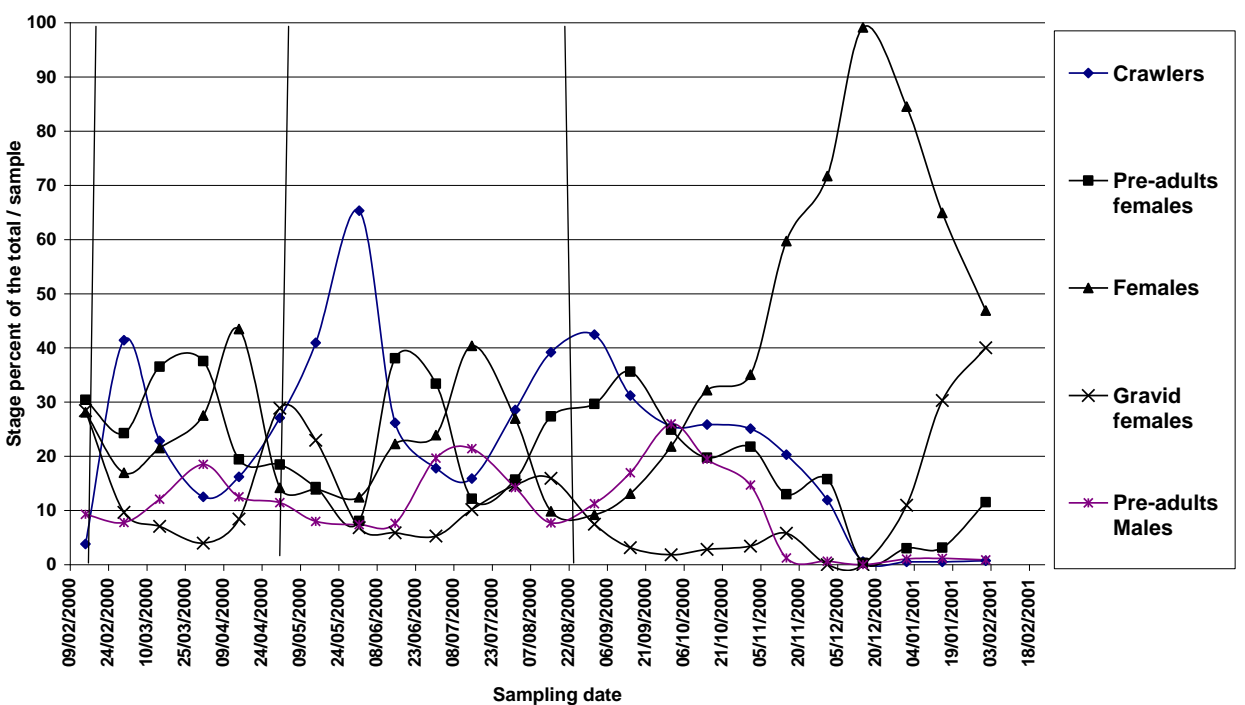

Fig . 9. Age-structure of pseudaulacaspis pentagona on plum trees during Mer. 2000 to 15 Feb. 2001 at El-Saff, Giza Governorate. 


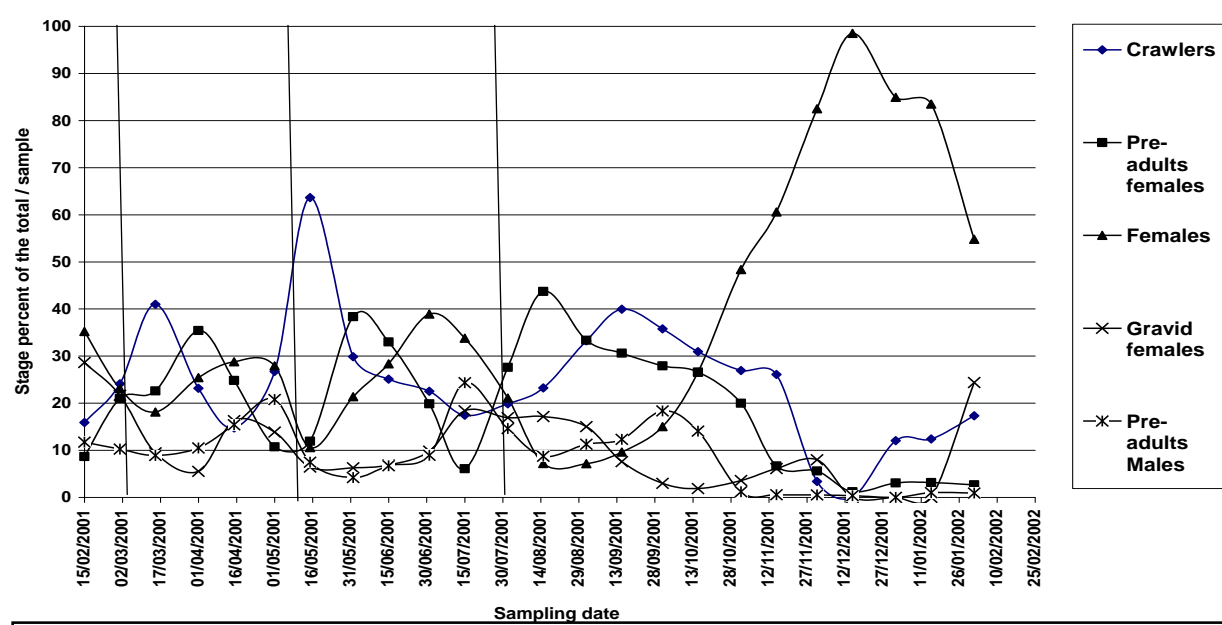

Fig . 10. Age-structure of pseudaulacaspis pentagona on plum trees during Mer. 2001 to 15 Feb. 2002 at El-Saff, Giza Governorate.

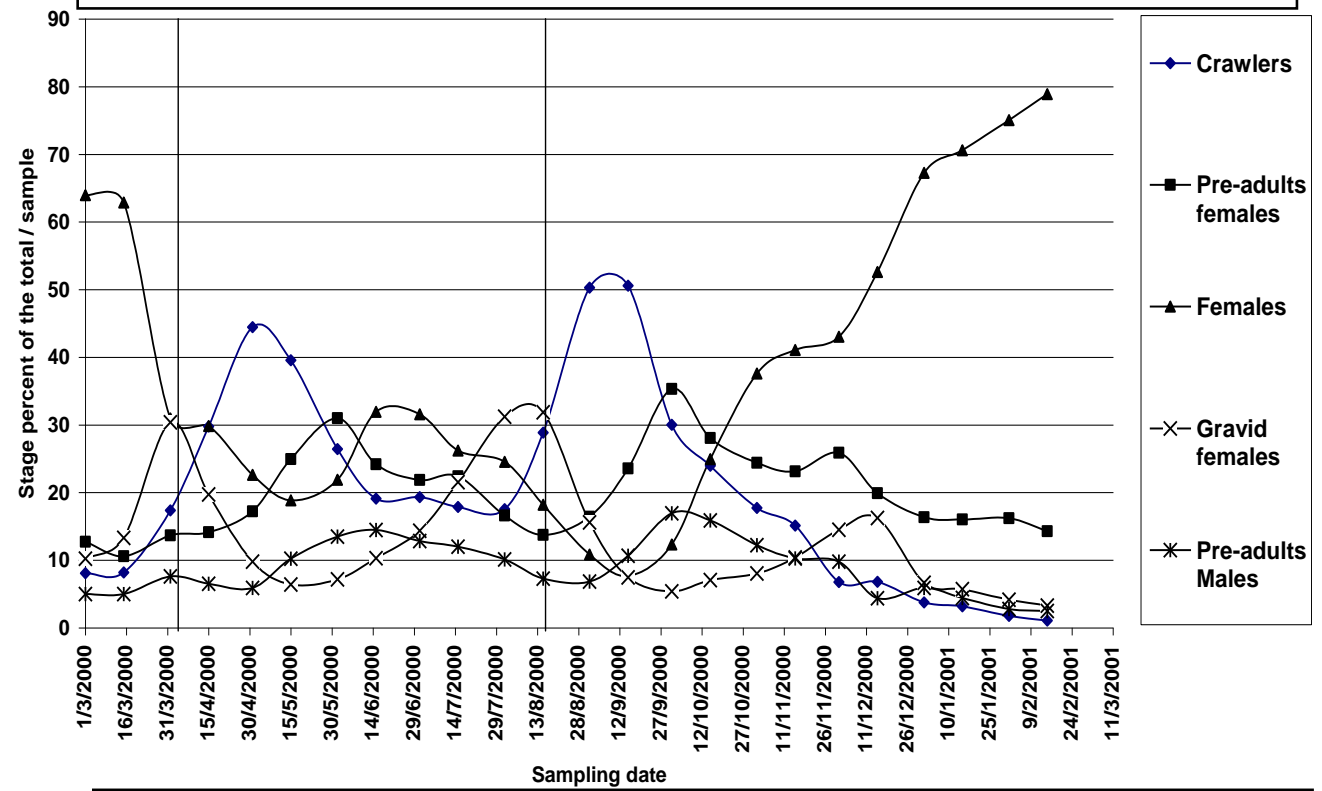

Fig . 11. Age-structure of pseudaulacaspis pentagona on apple trees during Mar. 2000 to 15 Feb. 2001 at El-Noubaria, El-Beheira, Governorate.
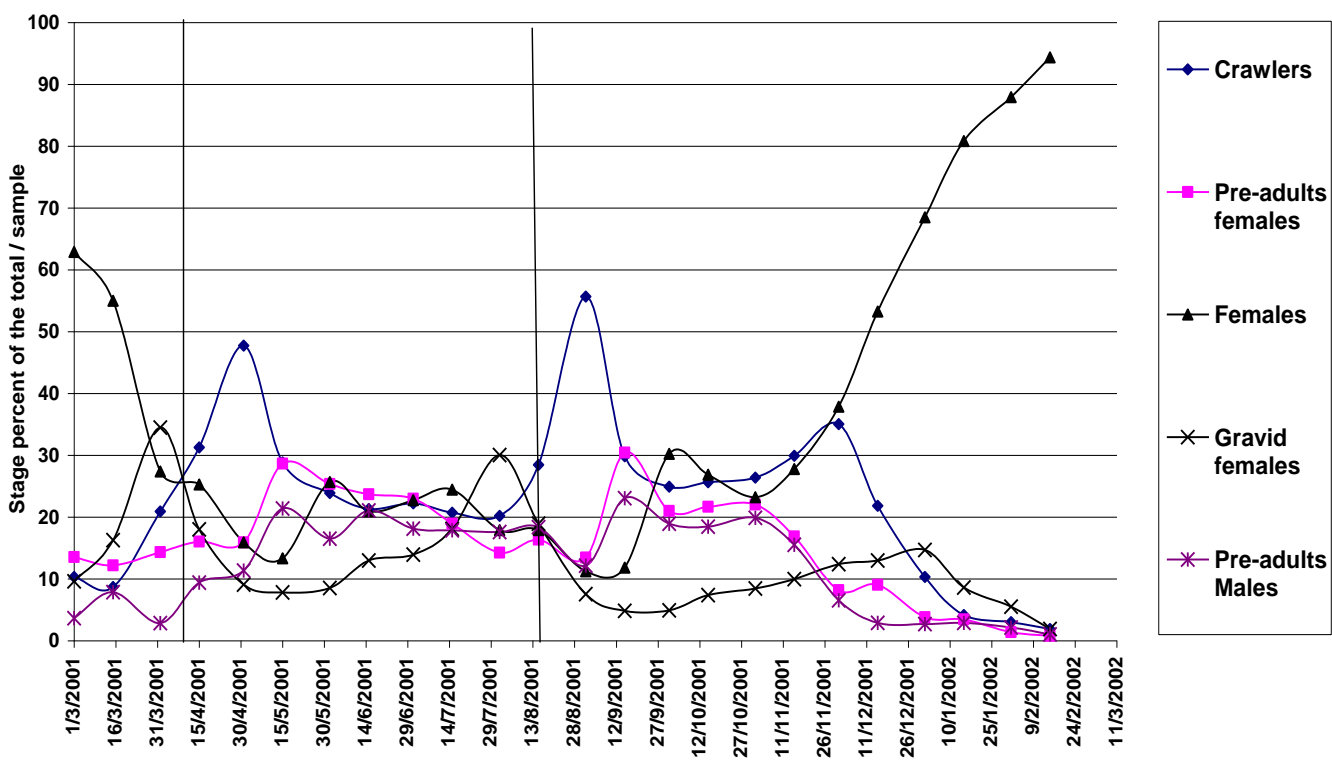

Fig . 12. Age-structure of pseudaulacaspis pentagona on apple trees during Mar. 2001 to Feb. 2002 at El-Noubaria, El-Beheira, Governorate. 


\section{Age structure and generation determination}

This method determining generation number is proper in case of the existing all developmental stages at the same niche. The advantage of this method over using the absolute population counts that it overcomes sampling errors. In the case of scale insects this method seems to be more accurate for generation determination where absolute counts may resemble actual generations as art of facts.

This method also is useful in determining the proper time for introducing control measurements being biological or chemical. This fact is based on introducing these measurements when the susceptible stage is at the most relative abundance.

The technique of using the age structure for determining the generations for scale insects has been reported by Mohamed (2002) who reported three generations for Parlatoria oleae on olive at Ismailia (regardless of olive variety). Serag (2005) used the same technique on fig at northern cost of Egypt. He reported three generations for both $L$. ficus and $H$. lataniae while reported two generations only for $R$. pustulans on the same host.

\section{ACKNOWLEDGEMENT}

This work was a part of Ph. D. requirements of the last author.

\section{REFERENCES}

1. Battaglia, D., A. di Leo, P. Malinconico, G. Rotundo and A. Di. Leo. 1994. Observations on white scale insect of peach and mulberry in Basilicata. Informatore Agrario. 50(3): 77-80.

2. Beardsley, J. w. and R. H. Gonzalez. 1975. The biology and ecology of armored scale. Ann. Rev. Entomol., 20, 47-73.

3. Bianchi, A., L. Guarino, E. Maffeo and A. Pacchiacucchi. 1995. Observations on Pseudaulacaspis pentagona and its natural enemies. Informatore Agrario. 51(45): 47-50.

4. Brailoiu, T. D. 1998. White peach scale Pseudaulacaspis pentagona (TargioniTozzetti) (Homoptera: Diaspididae) damage, identification, biology and control in Bucharest-Baneasa area. Zhivotnov"dni-Nauki. No. supplement, 10 -11.

5. Chen, C.T and CIT. Shih. 1984. Seasonal population abundances of white peach scale, Pseudaulacaspis pentagona (Targ.) and its parasitoids. J. Agric \& Forestry. 33(1): 57- 63.

6. Ding, XueYi and XY Ding. 2003. Biology and control of Pseudaulacaspis pentagona on oil nane. Entomol. Knowledge. 40 (3): 264-265. 
7. Erkilic, L., N. Uygun, KRS Ascher and Y. Ben-Dov. 1995. Distribution, population fluctuations and natural enemies of the white peach scale, Pseudaulacaspis pentagona (Targioni Tozzetti) (Homoptera: Diaspididae) in the east mediterranean region of Turkey. Israel J. Entoml. 29: 191-198.

8. Gardonna, A. P. and G. Viggiani. 1988. Observations on the white peach scale (Pseudaulacaspis pentagona Targ.-Tozz.) and its natural enemies in Campania. Ann. Facolta di Sci. Agric.della Univ. degli Studi di Napoli, Portici, IV. 22: 1-10.

9. Kosztarab, M. and F. Kozar. 1988. Scale insects of Central Europe, Akademiai Kiado, Budapest, 456 pp.

10. Kreiter, P. and L. Dijoux. 1998. White peach scale in a peach orchard. A control example in the Maritime Alps. Phytoma. France. 50: 36-40.

11. Mohamed, S. M. 2002. Environmentally safe approaches for controlling some scale insects infesting olive trees in new reclaimed areas. M. Sc. Thesis, Institute of Environmental Studies \& Research. Ain Shams Univ., Egypt, 112 pp.

12. Nalepa, C. and J. R. Meyer. 1990. The seasonal history of the white peach scale (Homoptera: Diaspididae) and its hymenopteran natural enemies in North Carolina. J. Entomol. Sci. 25(2): 303-310.

13. Pan- Wenxian , Qian- YinCai, Zhu- Wei, Jiang- XiaoFan, Pan- WX, Qian- YC, ZhuW. and Jiang- XF. 2003. Occurrence and control of Pseudaulacaspis pentagona in the Northern Zhejiang. J. Zhejiang Forestry Sci. and Technol. 23(1): 44-46.

14. Serag, A. M. 2005. Ecological and Toxicological studies on some pests attacking fig trees in Egypt. Ph. D. Thesis, Fac. Sci. Ain Shams Univ., Egypt, 234 pp.

15. Zhou, DaQiao and D. Q. Zhou. 1999. The occurrence of mulberry white scale on peach trees and its control. China-Fruits. No. 3, 53 pp. 


\section{دراسات بيئية على حشرة الخوخ القشرية البيضاء}

\section{جمال الدين حسين محمد ، زينات كمال الدين محمد ، فاطمة عبد الحليم محرم

$$
\text { معهُ بحوث وقاية النباتات ، مركز البحوث الزراعية ، الدقى- الجيزة }
$$

تضمنت هذه الدراسة التذبذب فى الكثافة العددية لحشرة الخوخ القشرية البيضاء على أشجار الخوخ فى منطقة كفر شكر محافظة القليوبية و على اشجار البرقوق فى منطقة الصف محافظة الجيزة

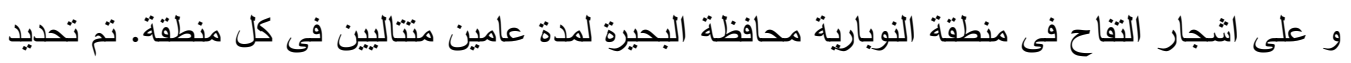

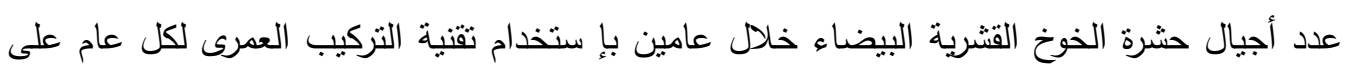
كل عائل نباتى فى كل منطقة.

أظهرت النتائج أن لهذه الحشرة ثلاثة أجيال في العام على أثجار الخوخ و البرقوق بمحافظتى

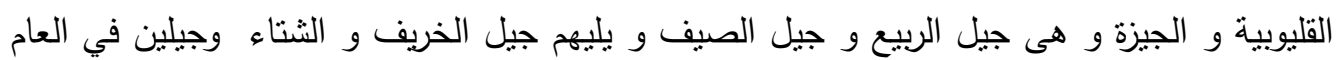

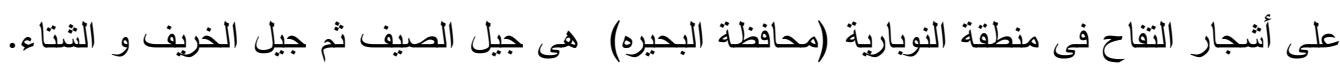

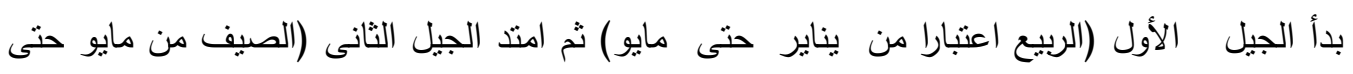

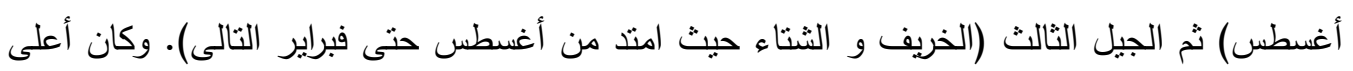
كثافة لتعداد حشرة الخوخ القشرية البيضاء فى جيل الخريف و الثتاء وكانت الكثافة العددية للحشرة أعلى فى جيل الربيع عن جيل الصيف. 